\title{
Raman Spectroscopy as a Potential Tool for Label Free Therapeutic Drug Monitoring in Human Serum: the Case of Busulfan and Methotrexate
}

\author{
Drishya Parachalil \\ Technological University Dublin \\ Franck Bonnier \\ Technnlogical University Dublin \\ Deirdre Commerford \\ Université de Tours
}

See next page for additional authors

Follow this and additional works at: https://arrow.tudublin.ie/nanolart

Part of the Chemistry Commons

\section{Recommended Citation}

Parachalil, D. et al (2019). Raman spectroscopy as a potential tool for label free therapeutic drug monitoring in human serum: the case of busulfan and methotrexate. Analyst, 144, pp.507-5214. doi:10.1039/C9AN00801B

This Article is brought to you for free and open access by the NanoLab at ARROW@TU Dublin. It has been accepted for inclusion in Articles by an authorized administrator of ARROW@TUDublin. For more information, please contact arrow.admin@tudublin.ie, aisling.coyne@tudublin.ie,gerard.connolly@tudublin.ie.

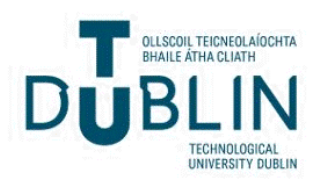




\section{Authors}

Drishya Parachalil, Franck Bonnier, Deirdre Commerford, Igor Chourpa, Jennifer Mclntyre, and Hugh J. Byrne

This article is available at ARROW@TU Dublin: https://arrow.tudublin.ie/nanolart/88 


\title{
Raman spectroscopy as a potential tool for label free therapeutic drug monitoring in human serum: the case of Busulfan and Methotrexate
}

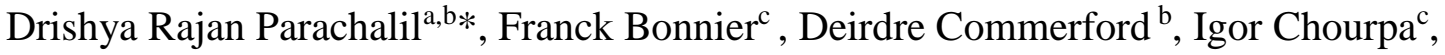
Jennifer McIntyre ${ }^{a}$, and Hugh J. Byrne ${ }^{a}$

${ }^{a}$ FOCAS Research Institute, Technological University of Dublin, Kevin Street, Dublin 8, Ireland

${ }^{c}$ Université de Tours, UFR sciences pharmaceutiques, EA 6295 Nanomédicaments et Nanosondes, 31 avenue Monge, 37200 Tours, France.

${ }^{b}$ School of Physics and Optometric \& Clinical Sciences, Technological University of Dublin, Kevin Street, Dublin 8, Ireland

*Corresponding Author: drishyarajan.parachalil@mydit.ie

\begin{abstract}
A methodology is proposed, based on Raman spectroscopy coupled with multivariate analysis, to determine the Limit of Detection (LOD) and Limit of Quantification (LOQ) for therapeutic drug monitoring in human serum, using the examples of Busulfan, a cell cycle non-specific alkylating antineoplastic agent, and, Methotrexate, a chemotherapeutic agent and immune system suppressant. In this study, ultrafiltration is employed to fractionate spiked human pooled serum to efficiently recover the drug in the filtrate prior to performing Raman analysis. The drug concentration ranges were chosen to encompass the recommended therapeutic ranges and toxic levels in patients. Raman spectra were collected from the filtrates in the liquid form, using an inverted backscattering microscopic geometry, using 532nm as source. Finally, prediction models were built by using Partial Least Squares Regression (PLSR) and LOD and LOQ were calculated directly from the linear prediction models. The LOD calculated for Busulfan is $0.0002 \pm 0.0001 \mathrm{mg} / \mathrm{mL}, 30-40$ times lower than the level of toxicity, enabling the application of this method in target dose adjustment of Busulfan for patients undergoing, for example, bone marrow transplantation. The LOD and LOQ calculated for Methotrexate are 7.8
\end{abstract}


$\pm 5 \mu \mathrm{M}$ and $26 \pm 5 \mu \mathrm{M}$, respectively, potentially enabling high dose monitoring. The promising results obtained from this study suggest the potential of Raman spectroscopy for therapeutic drug monitoring of drugs in bodily fluids.

\section{Keywords:}

Raman spectroscopy, Therapeutic Drug Monitoring, Busulfan, Methotrexate, Limit of detection, Limit of quantification, Partial least squares regression analysis 


\section{Introduction}

Therapeutic drug monitoring (TDM) refers to the clinical practice of management of a patient's drug dosage within a targeted therapeutic window, based on measurement of concentration of the drug in the bloodstream at timed intervals. For drugs with a narrow therapeutic range, such monitoring is essential to provide individualised patient treatment, while maintaining the efficacy of drugs and minimising drug toxicity and related adverse effects $(1,2)$.

TDM has also been increasingly advocated to improve the standard of chemotherapy, in which side effects can be substantial and life threatening (3-6). The currently available technique of chemotherapeutic-dosage calculation based on dose intensity and body surface area has been reported to be inaccurate for patients undergoing sustained chemotherapeutic treatment $(7,8)$. In the era of rising cost of healthcare, it is necessary to develop a rapid, sensitive, and costeffective, point-of-care technique for TDM, which can quantitatively measure the serum concentration of drugs, such that the dosing strategy can be tailored to the metabolism of an individual patient for a personalised therapeutic regime.

Busulfan $(\mathrm{Bu})$ is a bi-functional alkylating agent (see chemical structure in inset of Figure $2 \mathrm{~A}$ ) used in the chemotherapy-based conditioning regimen for hematopoietic stem cell transplantation (HSCT) (9-17). Bu has a very narrow therapeutic index, and higher systemic exposure to $\mathrm{Bu}$ is related to hepatic sinusoidal obstruction syndrome, neurotoxicity or insterstitial pneumonia, while low levels have been shown to be associated with increased incidence of graft rejection (18-21). Measurement of individual serum Bu levels during oral or intravenous dosing is likely to provide the necessary elements to monitor the drug disposition, ensuring efficacy, reduced incidences of toxicity and graft rejection (18-22). Several analytical methods, including chromatographic techniques coupled with a number of detection methods, have been described for analysing $\mathrm{Bu}$ in biological fluids; Gas chromatography (GC) with electron capture detection, high performance liquid chromatography (HPLC) with UV 
detection, GC-Mass spectroscopy (MS) with selected ion monitoring, and Enzyme linked immunosorbent assays (ELISA) have been reported to have high sensitivity for monitoring $\mathrm{Bu}$ in biological fluids $(10,11,23-26)$. However, the translation of these techniques to a routine analytical tool in a clinical setting for TDM is impractical, owing to their complexity and cost. Methotrexate (MTX) is a folate antagonist (see chemical structure in the inset of Figure 2B) widely used as an anti-cancer agent to treat various malignancies, such as leukemia, breast cancer, lymphomas and autoimmune diseases (27). MTX is administered in both low and high dosage (LDMTX and HDMTX), and monitoring serum MTX concentrations is essential to avoid high dosage related side effects (28). Serum MTX concentrations can vary from $10 \mathrm{nM}$ to $1 \mathrm{mM}$ for different patients, due to pharmacokinetic variability (28). The serum MTX concentration should reach between $10 \mu \mathrm{M}(0.001 \mathrm{mM})$ and $100 \mu \mathrm{M}(0.01 \mathrm{mM})$ after $12-36$ hours of HDMTX infusion and should reduce to $0.2 \mu \mathrm{M}$ after 72 hours. From the clinical point of view, it is essential to be able to detect the serum concentrations of MTX between $0.1 \mu \mathrm{M}$ and $10 \mu \mathrm{M}$, as high toxicity related adverse effects are associated with concentrations $>10 \mu \mathrm{M}$ $(28,29)$. Various sophisticated analytical tools such as Enzyme multiplied immunoassay technique (30), radioimmunoassay (31), enzyme exhibition assays (32), capillary zone electrophoresis (33) and liquid chromatography coupled with tandem mass chromatography (HPLC-MS/MS)(6,34-39) have been reported for TDM of MTX from biological fluids. Although immunoassays (40) and separation techniques (38) are routinely employed due to, they suffer from major limitations such as interferences from other compounds and lack of availability for all the drugs currently monitored (4). HPLC-MS/MS is considered the gold standard method for MTX (35-39) analysis due to its high sensitivity and robustness; however, it is time consuming, expensive and requires skilled personnel.

In recent years, Surface enhanced Raman spectroscopy (SERS) has been reported to be a good candidate for TDM of MTX $(28,29,41)$, doxorubicin (42), paclitaxel and cyclophosphamide 
(3) in biological fluids, since quantitative analysis of drugs can be performed rapidly and higher sensitivity. By comparison, quantification of $\mathrm{Bu}$ in biological fluids using spectroscopic techniques has not been explored. Critical issues of using SERS for TDM include development of standardised substrates, intense surface enhanced resonance SERS responses from other biological molecules such as carotenoids and also the spectral interference from the fluorescence that could interfere with the drug detection $(28,43)$. Therefore, new techniques that are inexpensive, less complex and faster are essential to quantitatively determine the concentration of drugs in a clinical setting. Herein, a rapid drug screening strategy using Raman spectroscopy coupled with ultrafiltration and multivariate analysis technique for $\mathrm{Bu}$ and MTX from liquid serum that yields a significant improvement in detection capabilities and minimises error is explored.

\section{Materials and Methods}

\section{Materials}

Methotrexate (A6770), Busulfan (B058) and human pooled serum (H6194) were purchased from Sigma Aldrich, Ireland. Stock solutions of $0.1 \mathrm{mg} / \mathrm{mL}$ Bu in methanol and $1 \mathrm{mM}$ MTX in $0.1 \mathrm{M} \mathrm{NaOH}$ were prepared. The spiked concentrations of $\mathrm{Bu}$ in serum are expressed in $\mathrm{mg} / \mathrm{mL}$ and MTX in $\mu \mathrm{M}$ to be consistent with previous studies $(4,29)$. The commercial human serum was spiked with Bu and MTX over the therapeutically relevant concentration ranges, to achieve the final concentrations of $(0-0.05 \mathrm{mg} / \mathrm{mL})$ for $\mathrm{Bu}$ and $(0-100 \mu \mathrm{M})$ for MTX. The normal therapeutic range for $\mathrm{Bu}$ is $0.0005 \mathrm{mg} / \mathrm{mL}$ to $0.005 \mathrm{mg} / \mathrm{mL}$ and any concentration below $0.0005 \mathrm{mg} / \mathrm{mL}$ can cause transplant failure, or higher than $0.005 \mathrm{mg} / \mathrm{mL}$, transplant related mortality (11), whereas for MTX, $1 \mu \mathrm{M}$ to $10 \mu \mathrm{M}$ and $<10 \mu \mathrm{M}$ is considered toxic (29). Raman spectra of highly concentrated $\mathrm{Bu}$ and MTX drug solutions prepared with a minimal amount 
of water $(\sim 1 \mathrm{mg} / \mathrm{mL})$ are used as the reference for the Extended Multiplicative Signal Correction algorithm (see Data pre-processing and analysis ).

Amicon Ultra 0.5mL centrifugal filter devices (Millipore- Merck, Germany), with a cut off point of $10 \mathrm{kDa}$, were employed to fractionate the serum samples. The centrifugation procedure previously reported by Bonnier et al. was followed (44). The optimised washing and rinsing procedure includes spinning $0.5 \mathrm{~mL} 0.1 \mathrm{M} \mathrm{NaOH}$ at $14000 \times \mathrm{g}$ for 30 minutes, followed by three rinses with distilled water by spinning $0.5 \mathrm{~mL}$ distilled water for 30 minutes at $14000 \times \mathrm{g}$. Every 30 minute wash and rinse must be followed by spinning the device in the inverted position at $1000 \times \mathrm{g}$ for 2 minutes, to remove the residual solution contained in the filter. After washing, $0.5 \mathrm{~mL}$ of spiked serum solution is transferred to the $10 \mathrm{kDa}$ filter and centrifuged at $14000 \times \mathrm{g}$ for 30 minutes. The filtrate that passes through the $10 \mathrm{kDa}$ filter contains mostly water and molecules smaller than $10 \mathrm{kDa}$. All the filtrate solutions were analysed using Raman spectroscopy and five replicate measurements from different positions have been recorded. In subsequent analysis, each dosed serum sample is represented by all the spectra recorded from that sample, rather than the mean.

\section{Raman spectroscopy}

The measurement conditions used for screening analytes in human serum in the liquid form have recently been detailed $(45,46)$. Raman spectra of all the liquid serum filtrate samples and references were recorded at stabilised room temperature $\left(18^{\circ} \mathrm{C}\right)$ using a Horiba Jobin-Yvon LabRam HR800 spectrometer with a 16-bit dynamic range Peltier cooled CCD detector. A $532 \mathrm{~nm}$ laser was used, which had a power of $\sim 30 \mathrm{~mW}$ at the sample, with a 600 lines $/ \mathrm{mm}$ grating and the backscattered Raman signal was integrated for $3 \times 80$ seconds over the spectral range from $400-1800 \mathrm{~cm}^{-1}$. The spectrometer was coupled to an Olympus $1 \mathrm{X} 71$ inverted microscope and a x60 water immersion objective (LUMPlanF1, Olympus) was employed. The 
substrate used was a Lab-Tek plate (154534) with a 0.16-0.19mm thick, 1.0 borosilicate glass bottom, and was purchased from Thermo Fischer Scientific, Ireland.

\section{Data pre-processing and analysis}

The raw spectra were subjected to pre-processing techniques in Matlab before further analysis, to remove the background signal and reduce the noise. Smoothing of the raw data was done using the Savitzky-Golay method (polynomial order of 5 and window 13) and the rubberband method (45) was found to be appropriate to baseline correct the smoothed reference spectra of both the drugs. The 'rubberband' correction was carried out by wrapping a 'rubberband' of defined length around the ends of the spectrum to be corrected and fitting against the curved profile of the spectrum. An adapted Extended Multiplicative Signal Correction (EMSC) algorithm (47), with a 3rd order polynomial, was applied to remove the underlying water spectrum from all the dataset, whose $\mathrm{OH}$ bending feature at $1640 \mathrm{~cm}^{-1}$ can interfere with the analyte spectra, and also scales the analyte spectra, assuming a constant water contribution to all sample spectra (47).

\section{Partial Least Squares Regression}

Partial Least Squares Regression (PLSR) was employed to establish a model that relates the variations of the spectral data to a series of concentrations. This regression model can be used to establish the limit of detection and quantitation of Raman bio-sensing of drugs $(48,49)$.

Constructed based on the spectra of samples of known drug content, over a range of varying concentrations of drug (in commercial serum), the model is then validated using a rigorous cross validation procedure which evaluates its performance in accurately predicting drug concentrations. For consistency with previous studies $(45,46)$, a 20 fold cross validation approach has been employed to validate the robustness of the method. This approach involves 
randomly dividing the set of observations into approximately equal size, $50 \%$ of the spectral data were randomly selected as test set, while the remaining $50 \%$ is used as the training set (50). The cross-validation process is then repeated 20 times (the folds), whereby all observations are used for both training and testing, and each observation is used for testing exactly once. The results from the folds can then be averaged to produce a single estimation. The Root Mean Square Error of Cross Validation (RMSECV) is calculated from the 20 iterations to measure the performance of the model for the unknown cases within the calibration set. The correlation between the true and predicted concentrations is given by the $\mathrm{R}^{2}$ value. The standard deviation was calculated to quantify the amount of variation in the dataset. The number of latent variables used for building the PLSR model is optimised by finding the value that is equivalent to the minimum of the RMSECV. The Limit of Detection (LOD) and Limit of Quantification (LOQ) of these two drugs for this method were calculated from the PLSR prediction plot, using a IUPAC-consistent approach previously reported for multivariate regression analysis by Ostra et al. (48).

$$
\begin{aligned}
& \text { LOD }=3 \times S_{\text {blank }} \times b \\
& \text { LOQ }=10 \times S_{\text {blank }} \times b
\end{aligned}
$$

where, $S_{\text {blank }}$ is the standard deviation of a blank (zero concentration sample) and $b$ is the slope of the regression (inverse calibration) model, in the region of linearity. The slope was calculated for the linear region of the prediction plot, including the standard deviation of each point, by initially regressing over the higher concentrations, and progressively adding smaller concentrations to the regression range, until the calculated slopes were seen to begin to reduce.

\section{Results and Discussion}

Figure 1 shows the schematic diagram of the strategy used to collect the $\mathrm{Bu}$ and MTX data from the serum samples to build the prediction models. 

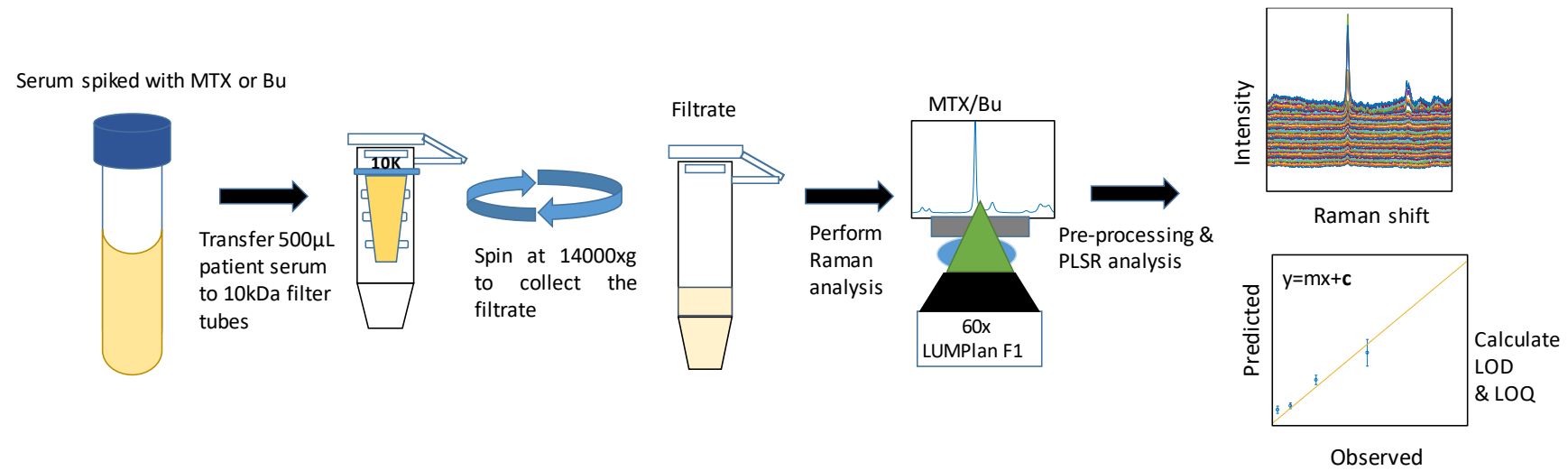

Figure 1. Schematic representation of the ultra-centrifugation, Raman analysis, data preprocessing and PLSR analysis of the Bu/MTX serum samples

The advantages of employing an inverted geometry to record Raman spectra have been detailed by Bonnier et al (51). The feasibility of using a Lab-Tek plate as substrate (45) and impact of ultra-filtration coupled with multivariate analysis techniques in detecting low molecular weight fraction analytes have also previously been reported $(46,52,53)$. The Raman spectra recorded from the $10 \mathrm{kDa}$ filtrate of $\mathrm{Bu}$ and MTX spiked serum samples were subjected to pre-processing steps followed by PLSR analysis. The whole finger print region $\left(400-1800 \mathrm{~cm}^{-1}\right)$ was chosen to build PLSR prediction for $\mathrm{Bu}$, whereas a shorter region, in which there are strong bands of MTX (1200-1800 $\left.\mathrm{cm}^{-1}\right)$, was chosen to facilitate efficient prediction of MTX by increasing the sensitivity. The improvement of the sensitivity of the prediction model for the case of glucose and urea when regressed over a reduced spectral region was previously reported $(46,54)$. The normal and toxic ranges of the $\mathrm{Bu}$ and MTX were encompassed by the range of spiked serum samples. 

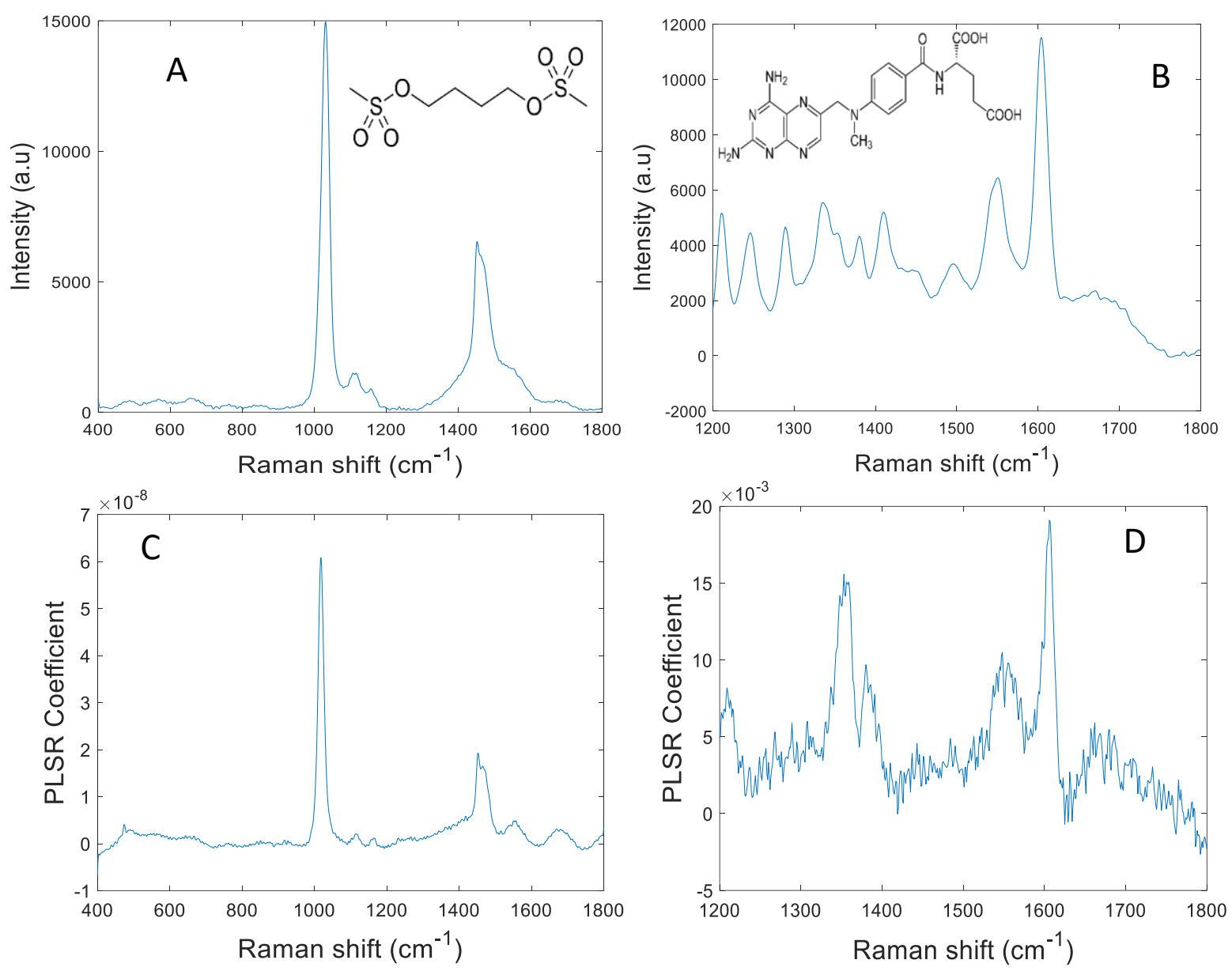

Figure 2.A: Reference spectrum of Bu used for EMSC correction. The chemical structure of $\mathrm{Bu}$ is shown in the inset. B: Reference spectrum of MTX used for EMSC correction. The chemical structure of MTX is shown in the inset. C: PLSR coefficient plot of Bu $\left(400-1800 \mathrm{~cm}^{-}\right.$ ${ }^{1}$ ) from serum filtrate concentrations showing spectral features similar to the Bu reference at $1097 \mathrm{~cm}^{-1}$ and $1453 \mathrm{~cm}^{-1}$. D: PLSR coefficient plot of regression against MTX from 1200$1800 \mathrm{~cm}^{-1}$ showing spectral features similar to the MTX reference at $1351 \mathrm{~cm}^{-1}$, and $1593 \mathrm{~cm}^{-1}$. RMSECV were calculated to be $0.0003 \mathrm{mg} / \mathrm{mL}$ for Bu and $4.02 \mu \mathrm{M}$ for MTX, respectively

Figure $2 \mathrm{~A}$ shows the reference spectrum of $\mathrm{Bu}$, and the signature peaks of $\mathrm{Bu}$ at $1097 \mathrm{~cm}^{-1}$ and $1453 \mathrm{~cm}^{-1}$, which can be ascribed to a $\mathrm{CH}_{2}$ scissoring mode and $\mathrm{C}-\mathrm{C}$ stretching, respectively (55). In the case of MTX, the signature peaks are a strong band at $1593 \mathrm{~cm}^{-1}$, which can be ascribed to the scissoring of the $\mathrm{NH}_{2}$ group, while the sharp band at $1351 \mathrm{~cm}^{-1}$ can be ascribed to $\mathrm{CH}_{2}$ scissoring vibrations (Figure $\left.2 \mathrm{~B}\right)(4,29,41)$. The pre-processed data set of systematically varied concentration of spiked, filtered serum (Figure S1A and B) is fed into the PLSR algorithm to build a prediction model that correlates the known concentration and the predicted concentration, based on the variation in spectral intensity, for each drug. On the basis of the 
percent variance explained by the latent variables and the lowest value of RMSECV, the total number of latent variables used to reach the best performance is calculated to be 3 for both $\mathrm{Bu}$ and MTX (Figure S3A and B). The RMSECV values are calculated to be $0.0003 \mathrm{mg} / \mathrm{mL}$ for Bu and 4.02 $\mu \mathrm{M}$ for MTX. The PLSR coefficient plots (Figure 2C and D) of Bu and MTX display Raman bands in good accordance with the reference ones, namely, the presence of peaks at $1097 \mathrm{~cm}^{-1}$ and $1453 \mathrm{~cm}^{-1}$ for $\mathrm{Bu}$, and $1593 \mathrm{~cm}^{-1}$, and $1351 \mathrm{~cm}^{-1}$ for MTX, respectively.
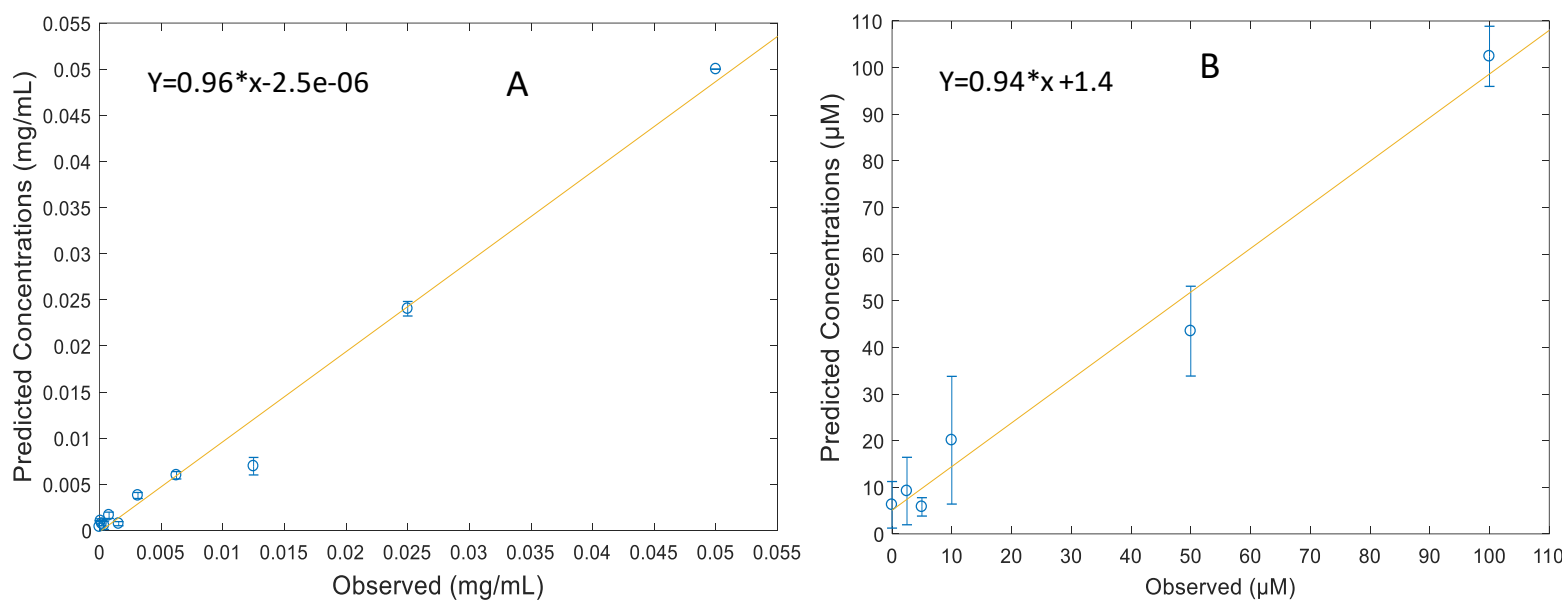

Figure 3: Linear predictive model for (A) Bu and (B) MTX built from the PLSR analysis. The LOD and LOQ for $\mathrm{Bu}$ were calculated to be $0.0002 \pm 0.0001 \mathrm{mg} / \mathrm{mL}$ and $0.00073 \pm 0.00010 \mathrm{mg} / \mathrm{mL}$, whereas the LOD and LOQ of MTX were calculated to be $7.8 \pm 5.0$ $\mu \mathrm{M}$ and $26 \pm 5 \mu \mathrm{M}$.

Figure $3 \mathrm{~A}$ and $\mathrm{B}$ indicate that the concentration dependence of the sample set is conserved by centrifugal filtration and a satisfactory linear model could be obtained for Bu and MTX from the filtrate of the serum samples. A linear prediction plot with a correlation accuracy $\left(\mathrm{R}^{2}\right)$ of 0.97 was obtained for $\mathrm{Bu}$, with an LOD of $0.0002 \pm 0.0001 \mathrm{mg} / \mathrm{mL}$ and LOQ of 0.00073 $\pm 0.0001 \mathrm{mg} / \mathrm{mL}\left(\mathrm{b}=0.96\right.$ and $S_{\text {blank }}=0.00008 \mathrm{mg} / \mathrm{mL}$ ), both in the acceptable range of clinical use. Figure S2A and B show that the signature peaks of Bu and MTX are discernible at the detection of limits identified by the respective PLSR models. Samples with Bu concentrations higher than $0.002 \mathrm{mg} / \mathrm{mL}$ are frequently observed in many hospitals, but, Bu concentrations less than $0.0005 \mathrm{mg} / \mathrm{mL}$ are rarely seen (11). This Raman spectral response was validated to be 
linear over the entire range of $0.0003 \mathrm{mg} / \mathrm{mL}$ to $0.0125 \mathrm{mg} / \mathrm{mL}$, which has not been fully validated in previous studies. In comparison to the earlier studies based on LC-MS, the present method shows similar performances in precision and recovery $(13,16,24,56)$. However, considering the time needed for sample preparation for the chromatography based methods, the present method has an added advantage that it does not require complex sample preparation steps. Besides, the amount of sample required for this method (1-50 $\mu \mathrm{L})$ is slightly less than that for other commonly employed methods (50 to $200 \mu \mathrm{L})(11)$. Thus, this proposed approach can be expeditiously implemented in laboratories in clinical settings for introduction of TDM of $\mathrm{Bu}$ to achieve safe and proper dosing.

Similarly, the correlation accuracy $\left(\mathrm{R}^{2}\right)$ is as high as 0.96 for MTX. The LOD was calculated to be $7.8 \pm 5.0 \mu \mathrm{M}$ and the LOQ to be $26 \pm 5 \mu \mathrm{M}\left(\mathrm{b}=0.94\right.$ and $\left.\mathrm{S}_{\text {blank }}=2.8 \mu \mathrm{M}\right)$. High risk of toxicity related adverse effects are associated with serum MTX concentrations of $>10 \mu \mathrm{M}$ $(4,29)$. The concentrations outside of safety values of MTX are $>10 \mu \mathrm{M}$ at 24 hours or $>1 \mu \mathrm{M}$ at 48 hours, and the serum MTX concentration should drop down to $0.2 \mu \mathrm{M}$ after 72 hours to reach the safety value $(4,29,57,58)$. For most drugs, the process of drug elimination is a firstorder rate process, and so, in a given patient, can be characterised by a rate constant (59). Therefore, from the clinical point of view, regular monitoring of MTX levels in patient serum can be used to determine a rate of drug elimination and help establish a personalised dosing regime for each patient. In previous studies, many researchers have reported the use of SERS substrates to detect MTX in plasma/serum with a LOD as low as $0.17 \mu \mathrm{M}$ (29). Although SERS gives promising results in detecting drugs at low concentrations in biological matrices $(28,29)$, qualitative variations within the SERS substrate (60), the interference of other biomolecules with the SERS spectra, makes quantification in real samples a challenging task (43). Alternatively, Bonifacio et al. demonstrated the use of Ag and Au colloids as SERS substrates to obtain intense and repeatable spectra from serum filtrate (61). 
In contrast, the proposed method with inverted Raman spectroscopy is cost-effective and easy to use, that can be translated as a point-of-care diagnostic tool for high-dosage MTX in bodily fluids. Notably, in determining the LOD and LOQ, while the slope of the concentration dependent response is dependent on the Raman scattering cross section of the analyte, the standard deviation of the blank is a measurement parameter, and instrument specific, and could potentially be improved by reduced noise and/or signal variability.

\section{Conclusion}

In summary, a rapid, sensitive, cost effective and reproducible method to determine the $\mathrm{Bu}$ and MTX levels in human serum has been demonstrated. In clinical practice, identification of individual therapeutic concentration of drugs is crucial for specific drugs with narrow therapeutic window by measuring the levels of these drugs at designated intervals in the serum/plasma, as the drug concentration in serum/plasma largely varies with time for different individuals based on their age, body weight, pregnancies, temporary illnesses, infections, emotional and physical stresses, accidents, and surgeries (12,58,62-64). TDM takes these factors into consideration and accommodates them while establishing an individual therapeutic concentration to fit the specific needs of a patient. This simple approach of Raman spectroscopy coupled with ultracentrifugation and multivariate analysis technique allows to effectively preserve the information in the filtrate while enabling easy detection of the drug concentration with higher accuracy. This strategy could be widely adopted for monitoring a variety of other drugs and small molecules. The present method accurately determines MTX concentrations at 7.8 $\pm 5.0 \mu \mathrm{M}$, suggesting that this method can be applied for high dose monitoring of MTX. On the other hand, this method determined the concentration of $\mathrm{Bu}$ as low as $0.0002 \pm 0.0001 \mathrm{mg} / \mathrm{mL}$, which is $30-40$ fold below the lowest Bu level that may present a risk for toxicity (19), thus ensuring effective and safe therapy for patients undergoing bone marrow transplant. Therefore, this can be a useful protocol for TDM of $\mathrm{Bu}$ to achieve safe and 
appropriate dosing. Further studies are needed to investigate the determination of these drugs in patient serum to ensure successful implementation of this method as a diagnostic tool. Thus far, this study is a proof of concept that simple Raman spectroscopy combined with multivariate analysis technique and ultrafiltration has the potential to be used as a diagnostic tool for therapeutic drug monitoring from human serum. 


\section{References}

1. Bowers LD. Analytical goals in therapeutic drug monitoring. Clin Chem. 1998;44(2):375-80.

2. Kang J, Lee M. Overview of Therapeutic Drug Monitoring. Korean J Intern Med. 2009;24(1):1-10.

3. Panikar SS, Ram G, Sidhik S, Lopez-luke T, Rodriguez-gonzalez C, Ciapara IH, et al. Ultrasensitive SERS Substrate for Label-Free Therapeutic-Drug Monitoring of Paclitaxel and Cyclophosphamide in Blood Serum. Anal. Chem. 2019, 91, 3, 21002111

4. Fornasaro S, Marta D, Rabusin M. Toward SERS-based point-of-care approaches for therapeutic drug monitoring : the case of methotrexate $\uparrow$. Faraday Discuss. 2016;187:485-99.

5. Mbarc Ă, Ilie M, Baconi DL, Ciobanu A, Balalau D, Burcea GT. Spectroflourimetric Methotrexate assay in human plasma.Farmacia. 2010;58:95-101.

6. Li H, Luo W, Zeng Q, Lin Z, Luo H, Zhang Y. Method for the determination of blood methotrexate by high performance liquid chromatography with online post-column electrochemical oxidation and fluorescence detection. J Chromatogr B Analyt Technol Biomed Life Sci. 2007,1;845(1):164-8

7. Gurney H. How to calculate the dose of chemotherapy. Br J Cancer. 2002 Apr 22; 86(8): 1297-1302.

8. Gurney H, Dodwell D, Tattersall MHN. Escalating drug delivery in cancer chemotherapy: A review of concepts and. Ann Oncol. 1993 Jan;4(1):23-34

9. Palmer J, Mccune JS, Perales M, Marks D, Bubalo J, Mohty M, et al. Biology of Blood and Marrow Transplantation Personalizing Busulfan-Based Conditioning : Considerations from the American Society for Blood and Marrow Transplantation 
Practice Guidelines Committee. Biol Blood Marrow Transplant. 2016;22(11):1915-25.

10. 10. Desire S, Mohanan EP, George B, Mathews V, Chandy M. A rapid \& sensitive liquid chromatography- tandem mass spectrometry method for the quantitation of busulfan levels in plasma \& application for routine therapeutic monitoring in haematopoietic stem cell transplantation. Indian J Med Res. 2013,137(4):777-84.

11. Moon SY, Lim MK, Hong S, Jeon Y, Han M, Song SH, et al. Quantification of Human Plasma-Busulfan Concentration by Liquid Chromatography-Tandem Mass Spectrometry. Ann Lab Med. 2014,34(1): 7-14

12. Yeh RF, Pawlikowski MA, Blough DK, Mcdonald GB, Donnell PVO, Rezvani A, et al. Accurate Targeting of Daily Intravenous Busulfan with 8-Hour Blood Sampling in Hospitalized Adult Hematopoietic Cell Transplant Recipients. Biol Blood Marrow Transplant. 18(2):265-72.

13. Salman B, Al-za M, Al-huneini M, Dennison D, Al-rawas A, Al-kindi S, et al. Therapeutic drug monitoring-guided dosing of busulfan differs from weight-based dosing in hematopoietic stem cell transplant patients. Hematol Oncol Stem Cell Ther. $2017 ; 10(2): 70-8$.

14. Choong E, Uppugunduri CRS, Marino D, Kuntzinger M, Doffey-Lazeyras F, et al. Therapeutic Drug Monitoring of Busulfan for the Management of Pediatric Patients : Cross-Validation of Methods and Long-Term Performance. Ther Drug Monit. 2018;40(1):84-92

15. Hassan BM, Ljungman P, Bolme P, Ringden O, Syrbekova Z, Bekhssy A, et al. Busulfan Bioavailability. Blood. 1994;84(7):2144-50

16. Veal GJ, Nguyen L, Paci A, Riggi M, Amiel M, Valteau-couanet D. Busulfan pharmacokinetics following intravenous and oral dosing regimens in children 
receiving high-dose myeloablative chemotherapy for high-risk neuroblastoma as part of the HR-NBL-1 / SIOPEN trial. Eur J Cancer. 2012;48(16):3063-72.

17. Schuler US, Ehrsam M, Schneider A, Schmidt H, Deeg J, Ehninger G.

Pharmacokinetics of intravenous busulfan and evaluation of the bioavailability of the oral formulation in conditioning for haematopoietic stem cell transplantation. Bone Marrow Transplant. 1998;22(3):241-4

18. Grochow LB, Jones RJ, Brundrett RB, Braine HG, Chen TL, Saral R, et al. Pharmacokinetics of busulfan: correlation with veno-occlusive disease in patients undergoing bone marrow transplantation. Cancer Chemother Pharmacol. 1989;25(1):55-61.

19. Ringde O, Ljungman P, Hassan M. High busulfan concentrations are associated with increased transplant- related mortality in allogeneic bone marrow transplant patients. Bone Marrow Transplantation, 1997;20:909-913

20. Slattery JT, Sanders JE, Buckner CD, Schaffer RL, Lambert KW, Langer FP, et al. Graft-rejection and toxicity following bone marrow transplantation in relation to busulfan pharmacokinetics. Bone Marrow Transplant. 1995;16(1):31-42.

21. Vassal G, Koscielny S, Challine D, Valteau-Couanet D, Boland I, Deroussent A, et al. Busulfan disposition and hepatic veno-occlusive disease in children undergoing bone marrow transplantation. Cancer Chemother Pharmacol. 1996;37(3):247-53.

22. Bolinger AM, Zangwill AB, Slattery JT, Risler LJ, Sultan DH, Glidden D V, et al. Target dose adjustment of busulfan in pediatric patients undergoing bone marrow transplantation. Bone Marrow Transplant. 2001;28(11):1013-8.

23. Chen TL, Grochow LB, Hurowitz LA, Brundrett RB. Determination of busulfan in human plasma by gas chromatography with electron-capture detection. J Chromatogr. 1988;425(2):303-9. 
24. Bleyzac N, Barou P, Aulagner G. Rapid and sensitive high-performance liquid chromatographic method for busulfan assay in plasma. J Chromatogr B Biomed Sci Appl. 2000; 742(2):427-32.

25. Quernin MH, Poonkuzhali B, Montes C, Krishnamoorthy R, Dennison D, Srivastava A, et al. Quantification of busulfan in plasma by gas chromatography-mass spectrometry following derivatization with tetrafluorothiophenol. J Chromatogr B Biomed Sci Appl. 1998;709(1):47-56.

26. Lombardi L R, Kanakry C G, Zahurak M, Bolaños-Meade J, et al. Therapeutic drug monitoring for either oral or intravenous busulfan when combined with pre- and posttransplantation cyclophosphamide. Leuk Lymphoma. 2016;57(3):666-75

27. Benedek TG. Methotrexate : from its introduction to non-oncologic therapeutics to anti-TNF- $\alpha$. Clin Exp Rheumatol. 2010;28(5 Suppl 61):S3-8.

28. Fornasaro S, Marta D, Rabusin M. Toward SERS-based point-of-care approaches for therapeutic drug monitoring : the case of methotrexate $\uparrow$. Faraday Discuss. Royal Society of Chemistry; 2016;00:1-15.

29. Hidi I J, Mühlig A, Jahn M, Liebold F, Cialla D, Weber K and Popp J. LOCSERS:towards point of care diagnosyic of methotrexate. Anal. Methods, 2014,6, 3943 3947

30. Shi X, Gao H, Li Z, Li J, Liu Y, Li L, et al. Modified enzyme multiplied immunoassay technique of methotrexate assay to improve sensitivity and reduce cost. BMC Pharmacology and Toxicology; 2019;5:1-7.

31. Langone JJ. Radioimmunoassay of methotrexate, leucovorin, and 5methyltetrahydrofolate. Methods Enzymol. 1982;84:409-22.

32. Widemann BC, Balis FM, Adamson PC. Dihydrofolate reductase enzyme inhibition assay for plasma methotrexate determination using a 96-well microplate reader. Clin 
Chem. 1999 Feb;45(2):223-8.

33. Kuo CY, Wu HL, Kou HS, Chiou SS, Wu DC, Wu SM. Simultaneous determination of methotrexate and its eight metabolites in human whole blood by capillary zone electrophoresis. J Chromatogr A. 2003;1014(1-2):93-101

34. Begas E, Papandreou C, Tsakalof A, Daliani D, Papatsibas G, Asprodini E. Simple and Reliable HPLC Method for the Monitoring of Methotrexate in Osteosarcoma Patients. J Chromatogr Sci. 2014;52(7):590-5.

35. Wu D, Wang Y, Sun Y, Ouyang N, Qian J. A simple, rapid and reliable liquid chromatography - mass spectrometry method for determination of methotrexate in human plasma and its application to therapeutic drug monitoring. Biomed Chromatogr. 2015;29(8):1197-202

36. Sonemoto E, Kono N, Ikeda R, Wada M, Ueki Y, Nakashima K. Practical determination of methotrexate in serum of rheumatic patients by LC-MS/MS. Biomed Chromatogr. 2012;26(11):1297-1300.

37. Rule G, Chapple M, Henion J. A 384-well solid-phase extraction for LC/MS/MS determination of methotrexate and its 7-hydroxy metabolite in human urine and plasma. Anal Chem. 2001;73(3):439-43.

38. Schofield RC, Ramanathan L V, Murata K, Grace M, Pessin MS, Carlow DC, et al. Development and validation of a turbulent flow chromatography and tandem mass spectrometry method for the quantitation of methotrexate and its metabolites 7hydroxy methotrexate and DAMPA in serum. J Chromatogr B Analyt Technol Biomed Life Sci. 2015 Oct 1;1002:169-75

39. Li Y, Li Y, Liang N, Yang F, Kuang Z. A reversed-phase high performance liquid chromatography method for quantification of methotrexate in cancer patients serum. $\mathbf{J}$ Chromatogr B. 2015;1002:107-12. 
40. Pesce MA, Bodourian SH. Evaluation of a fluorescence polarization immunoassay procedure for quantitation of methotrexate. Ther Drug Monit. 1986;8(1):115-21.

41. Yang J, Tan X, Shih W, Cheng MM. A sandwich substrate for ultrasensitive and labelfree SERS spectroscopic detection of folic acid / methotrexate. Biomed Microdevices. 2014 Oct;16(5):673-9

42. Sun F, Hung H, Sinclair A, Zhang P, Bai T, Galvan DD, et al. Hierarchical zwitterionic modification of a SERS. Nat Commun. 2016;7:1-9.

43. Jaworska A, Fornasaro S, Sergo V, and Bonifacio A. Potential of Surface Enhanced Raman Spectroscopy ( SERS ) in Therapeutic Drug Monitoring ( TDM ). Biosensors. 2016 Sep; 6(3): 47

44. Bonnier F, Blasco H, Wasselet C, Brachet G, Respaud R, Carvalho LFCS, et al. Ultrafiltration of human serum for improved quantitative analysis of low molecular weight biomarkers using ATR-IR spectroscopy. Analyst. 2017;142(8):1285-98.

45. Parachalil DR, Brankin B, McIntyre J, Byrne HJ. Raman spectroscopic analysis of high molecular weight proteins in solution - considerations for sample analysis and data pre-processing. Analyst. 2018;143(24):5987-98.

46. Parachalil DR, Bruno C, Bonnier F, Blasco H, Chourpa I, Baker MJ, et al. Analysis of bodily fl uids using vibrational spectroscopy : a direct comparison of Raman. Analyst, 2019, Advance Article

47. Kerr LT, Hennelly BM. A multivariate statistical investigation of background subtraction algorithms for Raman spectra of cytology samples recorded on glass slides. Chemom Intell Lab Syst; 2016;158:61-8.

48. Ostra M, Ubide C, Vidal M, Zuriarrain J. Detection limit estimator for multivariate calibration by an extension of the IUPAC recommendations for univariate methods. Analyst. 2008 ;133(4):532-9. 
49. Allegrini F, Olivieri AC. IUPAC-Consistent Approach to the Limit of Detection in Partial Least- Squares Calibration. Anal Chem. 2014;86(15):7858-66

50. Russell S, Norvig P. Artificial Intelligence: A Modern Approach. 3rd ed. Upper Saddle River, NJ, USA: Prentice Hall Press; 2009.

51. Bonnier F, Petitjean F, Baker MJ, Byrne HJ. Improved protocols for vibrational spectroscopic analysis of body fluids. J Biophotonics. 2014;7(3-4):167-79.

52. Bonnier F, Blasco H, Wasselet C, Brachet G, Respaud R, Carvalho LFCS, et al. Ultrafiltration of human serum for improved quantitative analysis of low molecular weight biomarkers using ATR-IR spectroscopy. Analyst. 2017;142(8):1285-1298

53. Bonnier F, Brachet G, Duong R, Sojinrin T, Respaud R, Aubrey N, et al. Screening the low molecular weight fraction of human serum using ATR-IR spectroscopy. J Biophotonics. 2016;9(10):1085-97.

54. Parachalil DR, Bruno C, Bonnier F, Blasco H, Chourpa I, et al. Raman spectroscopic screening of High and Low molecular weight fractions of human serum. (submitted to Analyst)

55. Karthick T, Tandon P, Singh S, Agarwal P, Srivastava A. Molecular and Biomolecular Spectroscopy Characterization and intramolecular bonding patterns of busulfan : Experimental and quantum chemical approach. Spectrochim Acta A Mol Biomol Spectrosc. 2017,173:390-399

56. Lin H, Goodin S, Strair RK, Dipaola RS, Gounder MK. Comparison of LC-MS Assay and HPLC Assay of Busulfan in Clinical Pharmacokinetics Studies. ISRN Analytical Chemistry. 2011, 2012:1-5

57. Nirenberg A, Mosende C, Mehta BM, Gisolfi AL, Rosen G. High-dose methotrexate with citrovorum factor rescue: predictive value of serum methotrexate concentrations and corrective measures to avert toxicity. Cancer Treat Rep. 1977 Aug;61(5):779-83. 
58. Lin F, Juan Y, Zheng S, Shen Z, Tang L. Relationship of Serum Methotrexate Concentration in High-Dose Methotrexate Chemotherapy to Prognosis and Tolerability: A Prospective Cohort Study in Chinese Adults With Osteosarcoma. Curr Ther Res. Excerpta Medica Inc. 2009;70(2):150-60.

59. Ahmed TA. Pharmacokinetics of Drugs Following IV Bolus, IV Infusion, and Oral Administration. Intech, 2015.

60. Fang Y, Seong NH, Dlott DD. Measurement of the distribution of site enhancements in surface-enhanced Raman scattering. Science. 2008;321(5887):388-92

61. Bonifacio A, Dalla Marta S, Spizzo R, Cervo S, Steffan A, Colombatti A, Sergo V. Surface-enhanced Raman spectroscopy of blood plasma and serum using Ag and $\mathrm{Au}$ nanoparticles: a systematic study. Anal Bioanal Chem. 2014;406(9-10):2355-65

62. Zao JH, Schechter T, Liu WJ, Gerges S, Gassas A, Egeler RM, et al. Biology of Blood and Marrow Transplantation Performance of Busulfan Dosing Guidelines for Pediatric Hematopoietic Stem Cell Transplant Conditioning. Biol Blood Marrow Transplant. 2015;21(8):1471-8.

63. Yeager BAM, Wagner JE, Graham ML, Jones RJ, Santos GW, Grochow LB. Optimization of Busulfan Dosage in Children Undergoing Bone Marrow Transplantation. Blood. 1992;80(9):2425-8

64. Wallace CA, Bleyer WA, Sherry DD, Salmonson KL, Wedgwood RJ.Toxicity and serum levels of methotrexate in children with juvenile arthritis. Arthritis Rheum. 1989;32(6):677-81. 